George A. Arndt MD, Samantha Buchika MD, Paul W. Kranner MD, Stephen T. DeLessio MD

\title{
Wire-guided endo- bronchial blockade in a patient with a limited mouth opening
}

Purpose: We report the use of wire-guided endobronchial blockade, a new method of achieving one-lung ventilation, in a patient requiring awake, nasal, fibreoptic intubation for resection of a lung carcinoma.

Clinical Report: A 43-yr-old woman with limited mouth opening, from severe TMJ dysfunction, required a right thoracotomy for right upper lobe wedge resection. One-lung ventilation was accomplished using a new type of wire-guided endobronchial blocker. The device was placed coaxially through the endotracheal tube using a pediatric bronchoscope through a special bronchoscopy port.

Conclusion: Effective one-lung ventilation was achieved using this system. The system may prove advantageous in clinical situations where placement of double lumen endotracheal tubes or Univent tubes is technically impractical or impossible.

Objectif : Nous décrivons un blocage endobronchique utilisant une tige métallique : une nouvelle méthode pour la ventilation pulmonaire unilatérale. Une patiente, admise pour résection d'un cancer pulmonaire, a dû subir une intubation fibroscopique nasale et vigile.

Résumé clinique : Une femme de 43 ans, qui présentait un sévère dysfonctionnement de l'articulation temporo-mandibulaire limitant l'ouverture de la bouche, devait subir une thoracotomie droite pour une résection cunéiforme du lobe supérieur droit. La ventilation d'un seul poumon a été réalisée à l'aide d'un nouveau bloqueur endobronchique sur tige métallique. L'appareil a été introduit de façon coaxiale dans le tube endotrachéal, conjointement avec un bronchoscope pédiatrique, à travers une fenêtre de bronchoscopie spéciale.

Conclusion : Une ventilation pulmonaire unilatérale efficace a été obtenue en utilisant cette technique. Ce dispositif pourrait être avantageux en clinique lorsqu'on juge l'emploi de tubes à double lumière ou Univent impossible ou impraticable.

From the Department of Anesthesiology, University of Wisconsin Clinical Sciences Center,B6/319 CSC, 600 Highland Avenuc, Madison, WI 53792-3272 USA.

Address correspondence to: George A. Arndt MD, Phone: 608-263-5447; Fax: 608-263-0575.

Accepted for publication October 22, 1998 
$\mathrm{P}$ ATIENTS with limited mouth opening present a challenge when requiring one-lung ventilation because intubation with a doublelumen or Univent endotracheal tube may be impossible. Wire-guided endobronchial blockade is a new method to achieve one-lung ventilation with a conventional endotracheal tube. The system allows rapid and precise placement of an endobronchial blocker using a pediatric bronchoscope and a special bronchoscopy port using a guide wire mechanism.

\section{Case report}

A 43-yr-old woman was scheduled to undergo a right thoracotomy for wedge resection of a presumed right upper lobe lung carcinoma. Several years earlier, she had sustained severe temporomandibular joint (TMJ) trauma in a motor vehicle accident, leading to multiple surgical procedures requiring nasal intubation secondary to jaw dysfunction. Preoperative examination revealed a mouth opening limited to $15 \mathrm{~mm}$.

Awake, nasal, fibreoptic intubation was chosen for this procedure. The airway was topicalized with a nebulized mist of lidocaine $4 \%$ and phenylephrine, followed by further topicalization and dilatation of the left nares with lidocaine $2 \%$ jelly on nasal airways. A $3.4 \mathrm{~mm}$ fibreoptic bronchoscope (Pentax, Tokyo, Japan) was loaded with a $7.5 \mathrm{~mm}$ endotracheal tube and passed into the trachea. The endotracheal tube was advanced, the scope withdrawn and the position confirmed with capnography. The patient tolerated the procedure well, and anesthesia was induced with thiopental, fentanyl, and muscle relaxation was provided by vecuronium.

The decision was made to use a wire-guided endobronchial blocker (WEB) to achieve one-lung ventilation for the procedure. The device was investigational, and informed consent was obtained following University of Wisconsin human subject protocol.

The WEB system is placed coaxially through a conventional endotracheal tube using a pediatric bronchoscope and special bronchoscopy port (SBP). The WEB (Cook Inc., Bloomington, IN) is a 9 French, $70 \mathrm{~cm}$, double-lumen catheter with $1.4 \mathrm{~mm}$ and $0.4 \mathrm{~mm}$ ID lumens (Figure 1). At the distal end is a $3 \mathrm{~cm}$, elliptical, low-pressure, high-volume balloon inflated via the 0.4 $\mathrm{mm}$ lumen. The $1.4 \mathrm{~mm}$ lumen contains a wire passing through a Leuer fitting at the proximal end of the catheter and extending to the distal end, where it exits as a small loop of approximately $6 \mathrm{~mm}$ diameter. The size of the loop can be varied by extending and retracting the wire within the Leuer fitting. Alternatively, the wire may be removed completely and the resulting free lumen used for suctioning or CPAP of the isolated lung.

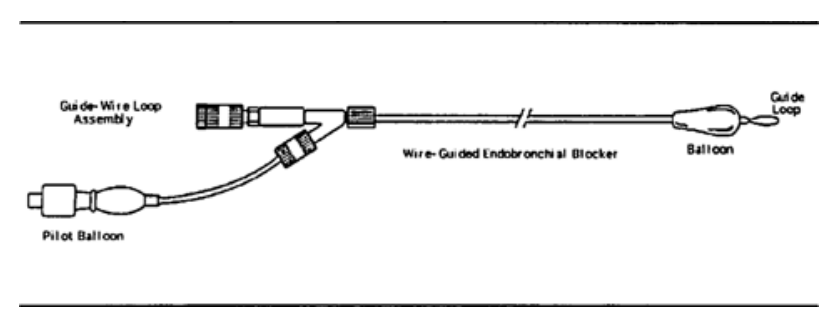

FIGURE 1 Wire-guided endobronchial blocker.

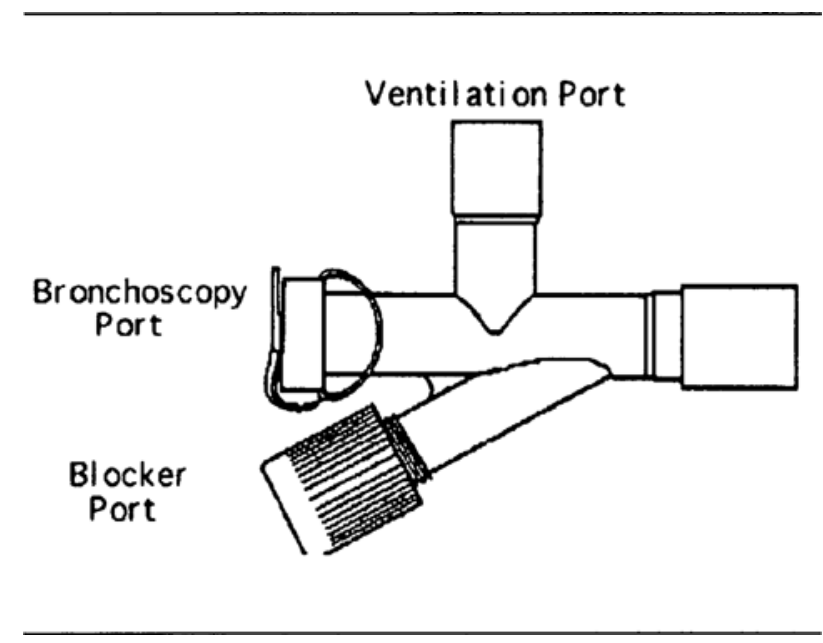

FIGURE 2 Special bronchoscopy port.

The WEB is placed through a SBP (Cook Inc., Bloomington, IN) (Figure 2). The SBP offers multiple access ports allowing simultaneous introduction of the bronchoscope and WEB while maintaining ventilation of the patient. The bronchoscopy port has a standard plastic sealing cap, while the WEB port has a TuohyBorst type connecter with a compressible diaphragmatic valve which locks the blocker in place and maintains an air-tight seal. The WEB port is oriented at a $30^{\circ}$ angle to the bronchoscopy port to facilitate introduction of both devices into the endotracheal tube.

Prior to placement of the endobronchial blocker, the WEB shaft, wire loop and fibreoptic bronchoscope were all lubricated with a medical grade silicone lubricant. The wire loop was adjusted to approximate loosely the outer diameter of the bronchoscope (3.4 mm OD Pentax, Tokyo, Japan) and the WEB passed through its port in the SBP. The SBP was then connected to the endotracheal tube and ventilation maintained while tightening of the WEB port connector prevented air leakage. The bronchoscope was advanced into the SBP and passed through the wire loop of the WEB, effectively coupling the two together. The scope was directed into the right mainstern 
bronchus, the WEB port connector cap was loosened and the WEB introduced until the wire loop slid off the end of the bronchoscope. As the scope was withdrawn, correct positioning of the blocker in the right mainstern bronchus was verified. Inflation of the balloon with $10 \mathrm{ml}$ air caused total occlusion of the bronchus, and a quiet surgical field was obtained. Exploration of the right lung and wedge resection proceeded uneventfully. At the conclusion of surgery, the balloon was deflated and the WEB system removed, allowing ventilation of both lungs for emergence from anesthesia.

\section{Discussion}

Patients with limited mouth opening present a clinical challenge, and awake fibreoptic intubation is a recommended technique of airway management. ${ }^{1}$ This patient required nasal intubation because her extremely limited opening precluded placement of an intubating airway or manual tongue traction during oral fibreoptic tube placement. The surgical need for one-lung ventilation was problematic as conventional double-lumen or Univent endotracheal tubes are large and cumbersome and their nasal placement is suboptimal or impossible. Endobronchial blockade with a Fogarty embolectomy catheter has been described, ${ }^{2}$ but also has several drawbacks. ${ }^{3-5}$ The Fogarty was designed for vascular embolectomy and, therefore, has a spherical balloon unlike those designed for airway use. Placement may be difficult, as it is unguided, and no lumen exists for adding or removing gas from the occluded segment. Finally, current bronchoscopy ports allow gas leakage to occur during the placement process and provide no good means of securing the blocker once it is in place.

The WEB system with the SBP was designed to overcome many of the pitfalls of current endobronchial blocker technology. Ventilation is easily maintained during placement of the blocker, which is quick and precise due to the wire guiding system. Removal of the wire following placement provides an open lumen for insufflation or gas exit from the isolated segment. The elliptical shape of the $3 \mathrm{~cm}$ balloon maximizes contact with the bronchial wall, helping prevent dislodgement by surgical manipulation. The SBP blocker port incorporates a compressible diaphragm within a threaded cap, forming an adjustable air-tight seal while locking the blocker in place. Finally, the entire system uses a conventional single-lumen endotracheal tube maximizing crosssectional diameter and eliminating the need to change tubes should postoperative ventilation be desired.

In conclusion, the WEB is a new device to achieve one-lung ventilation with a conventional endotracheal tube. It may offer advantages over conventional doublelumen or Univent tubes in certain situations. It effectively provided one-lung ventilation in this patient who required nasal intubation because of severe TMJ dysfunction.

\section{References}

1 Benumof JL. Management of the difficult adult airway. With special emphasis on awake tracheal intubation. Anesthesiology 1991; 75: 1087-110.

2 Ginsberg RJ. New technique for one-lung anesthesia using an endobronchial blocker. J Thorac Cardiovasc Surg 1981; 82: 542-6.

3 Arndt GA, Kranner PW, Lorenz DC. Co-axial placement of an endobronchial blocker (Letter). Can J Anaesth 1994; 41: 1126-7.

4 Larson CE. A device for endobronchial blocker placement during one-lung anesthesia (Letter). Anesth Analg 1990; 71: 311-2.

5 Zilberstein M, Katz RI, Levy A, Reyes R, Poppers PJ. An improved method for introducing an endobronchial blocker. J Cardiothorac Anesth 1990; 4: 481-3. 